Original Article

Open Access

\title{
VIROLOGICAL RESPONSES OF VELPATASVIR/SOFOSBUVIR IN PATIENTS WITH HCV GENOTYPE 3
}

\author{
Muhammad Sarfraz ${ }^{a}$, Arshad Rabbani ${ }^{b}$, Muhammad Shahzad Manzoor ${ }^{c}$, Benish Adil ${ }^{a}$, Ramsha Ghazal \\ Arshad $^{d}$ \\ aPost Graduate Resident, Department of Medicine Unit-ii, Benazir Bhutto Hospital, Rawalpindi. \\ ${ }^{b}$ Assistant Professor, Department of Medicine Unit-ii, Benazir Bhutto Hospital, Rawalpindi. \\ 'Professor, Department of Medicine, DHQ Hospital, Rawalpindi. \\ ${ }^{\mathrm{d}}$ House officer, Medicine Unit-ii, Holy Family Hospital, Rawalpindi.
}

\section{ABSTRACT:}

BACKGROUND \& OBJECTIVE: The role of Velpatasvir/Sofosbuvir in the treatment of hepatitis C virus type 3 infection is evaluated in terms of virologic responses. i.e Rapid Virological Response (RVR) End of treatment response (ETR) and Sustained virological response (SVR 12).

METHODOLOGY: This was a descriptive case study conducted in Liver OPD of Benazir Bhutto Hospital during 01 November 2018 to 30 April 2019, in which 100 patients of HCV were enrolled, all of them had HCV genotype 3 infection. Every patient was treated with combination of Velpatasvir/Sofosbuvir 100mg/400 mg Once Daily as part of treatment regimen of HCV infection for 12 weeks. Pre-treatment HCV RNA QUANTITATIVE PCR was done, which was repeated on 4, 12 weeks of treatment and then 12 weeks post treatment.

RESULTS: Among 100 patients, 51 (51\%) were male and 49 (49\%) were females. Mean age of patients was $43.2 \pm 10.4$ years (mean \pm SD). Mean BMI of enrolled patients was $21.34 \pm 2.40$ $\mathrm{kg} / \mathrm{m} 2.33 \%$ patients were cirrhotic while $67 \%$ were non cirrhotic. $53 \%$ patients were treatment experienced while 47\% were treatment naïve. Rapid Virological Response (RVR) was achieved in $92 \%$, End of treatment response (ETR) was achieved in 96\%, while Sustained Virological response (SVR12) was achieved in $99 \%$ patients. The results were stratified according to age, gender and BMI. There was no effect of these parameters on the final results.

CONCLUSION: Virological response (RVR, ETR, SVR12) of Velpatsvir /Sofosbuvir and Ribavirin is encouraging.

KEYWORDS: HCV, Genotype 3, RVR, ETR, SVR12, Oral Direct Acting Antivirals, DAA, Velpatasvir, Sofosbuvir.

doi: https://doi.org/10.37723/jumdc.v11i1.397

\section{How to cite this:}

Sarfraz M, Rabbani A, Manzoor MS, Adil B, Arshad RG. VIROLOGICAL RESPONSES OF VELPATASVIR/SOFOSBUVIR IN PATIENTS WITH HCV GENOTYPE 3. jumdc. 2020;11(1):9-14.

doi: https://doi.org/10.37723/jumdc.v11i1.397

This is an Open Access article distributed under the terms of the Creative Commons Attribution License (http://creativecommons.org/licenses/by/4.0), which permits unrestricted use, distribution, and reproduction in any medium, provided the original work is properly cited. 


\section{INTRODUCTION:}

Hepatitis C virus is a major global health concern. Worldwide above 170 million patients have HCV infection with more than 70 million people progress to chronic HCV infection and $\mathrm{HCV}$ related liver diseases ${ }^{[1]}$.There are 6 genotypes of HCV infection among which most abundant is HCV genotype 1 , but genotype of major concern in our part of world is $\mathrm{HCV}$ genotype 3 which is found to have infected $30.1 \%$ patients ${ }^{[2]}$.

$\mathrm{HCV}$ infection can be acute, but in majority cases it progresses to chronic infection which leads to cirrhosis predisposing to hepatocellular carcinoma posing greater health concerns and significant impact on morbidity and mortality ${ }^{[3]}$. Treatment guidelines of HCV management have evolved rapidly in current decade, since the start of use of direct acting oral antivirals (DAAs) in management of HCV infection.

There are two goals of HCV infection treatment. One is to achieve virological responses in term of sustained virological response which is defined as persistent absence of HCV RNA in serum after 12 weeks of completion of treatment with medications, other goal is to prevent complications of $\mathrm{HCV}$ such as development of cirrhosis and decompensated liver disease ${ }^{[4]}$.

Among recently approved combination Velpastavir/Sofosbuvir combination was approved by FDA in 2016. Velpatasvir is NS5A targeting agent and Sofosbuvir is NS5B targeting drug, both NS5A and NS5B are viral replication proteins ${ }^{[5]}$.

The efficacy of Epclusa (Velpatasvir/Sofosbuvir) was evaluated in ASTRAL-1, ASTRAL-2, ASTRAL- 3 and ASTRAL-4. SVR 12 was concluded to be $98 \%$ in ASTRAL1,2, and 3 after 12 weeks of treatment in ASTRAL 4 , Epclusa for 12 weeks and 24 weeks achieved $83 \%$ and $86 \%$ SVR 12 respectively ${ }^{[6,7,8]}$.

Currently there are no local studies available for evaluation of virological responses to Velpatasvir/Sofosbuvir combination. The aim of this study is to evaluate the efficacy of Velpatasvir/Sofosbuvir (Epclusa) in achieving virological responses in HCV genotype 3.
Corresponding Author:

Dr. Arshad Rabbani

Assistant Professor, Department of Medicine

Unit-ii, Benazir Bhutto Hospital, Rawalpindi

Email: arshabb@hotmail.com

\section{METHODOLOGY:}

This descriptive case study was conducted in Liver Clinic OPD of Medicine Unit-II, Benazir Bhutto hospital from 01-11-2018 to 30-042019 over six months' time. The study has been approved by the Ethical review committee of Benazir Bhutto hospital, Rawalpindi. Patients of HCV genotype 3 presenting in Liver clinic were enrolled in this study after taking informed consent via non-probability consecutive sampling technique. Patients with or without cirrhosis, and both treatment naïve and treatment experienced patients were included in study. Age of included patients was between $18-70$ years with $B M I>18 \mathrm{~kg} / \mathrm{m}^{2}$. All Patients had pretreatment HCV RNA Quantitative levels >1000 IU/L. Patients with HBV, HIV coinfection, pregnant women, and patients with decompensated liver disease were excluded. As a part of treatment regimen, Tab Velpatasvir/ Sofosbuvir (EPCLUSA) in dose of $100 \mathrm{mg} /$ $400 \mathrm{mg}$ once daily was given to all patients for 12 weeks. HCV RNA PCR QUANTITATIVE was done at 4 weeks of treatment for Rapid Virological Response, at 12 week of treatment for End of Treatment Response (ETR) and 12 weeks post treatment for Sustained Virological Response (SVR12) ${ }^{[9]}$.

All the categorical variables like gender, RVR, ETR, SVR were described as frequencies and percentages while for age, BMI which are continuous variables, mean and SD was calculated. Effect modifiers including age, gender, BMI were controlled by stratification.

\section{RESULTS:}

Total of 100 patients of HCV were evaluated. Mean age of patients was $43.2 \pm 10.4$ years (mean $\pm \mathrm{SD}$ ). 
The age was further distributed into two categories the distribution is given below in the graph (Figure I).

Out of 100 patients, 51 (51\%) were males and $49(49 \%)$ were females.

The following pie chart (Figure II) shows the distribution of male and female patients. The BMI was $21.34 \pm 2.40 \mathrm{~kg} / \mathrm{m} 2.33$ patients were having evidence of liver cirrhosis and Ultrasound at time of enrollment, whereas 67 patients were non-cirrhotic. $47 \%$ patients $(47 / 100)$ were treatment naïve, whereas remaining 53\% (53/100) had already taken. Rapid Virological Response(RVR) was achieved in $92 \%$ of patients (92/100), whereas End of treatment response was achieved in $96 \%$ (96/100) Patients and Sustained Virological Response (SVR12) was achieved in 99\% (99/100) patients. The following pie chart (Figure III) shows the distribution RVR, ETR and SVR among patients.

The data was stratified according to age, gender and BMI. There was no effect of these parameters on the final results. The following table (Table I) shows the comparison between groups for efficacy after stratification.

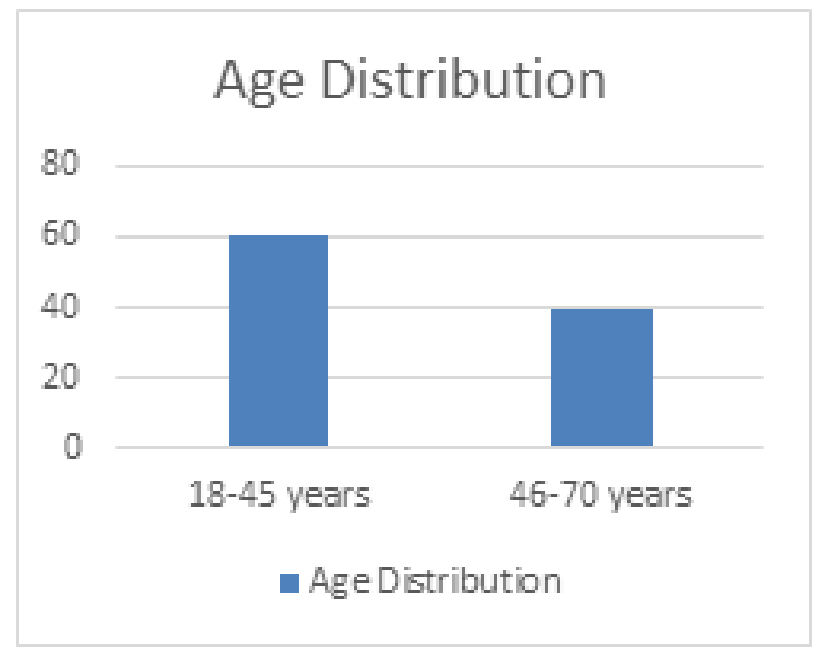

Figure-I

\section{Gender Distribution}

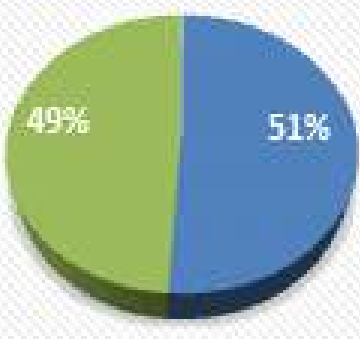

Males $=$ Females

Figure-II
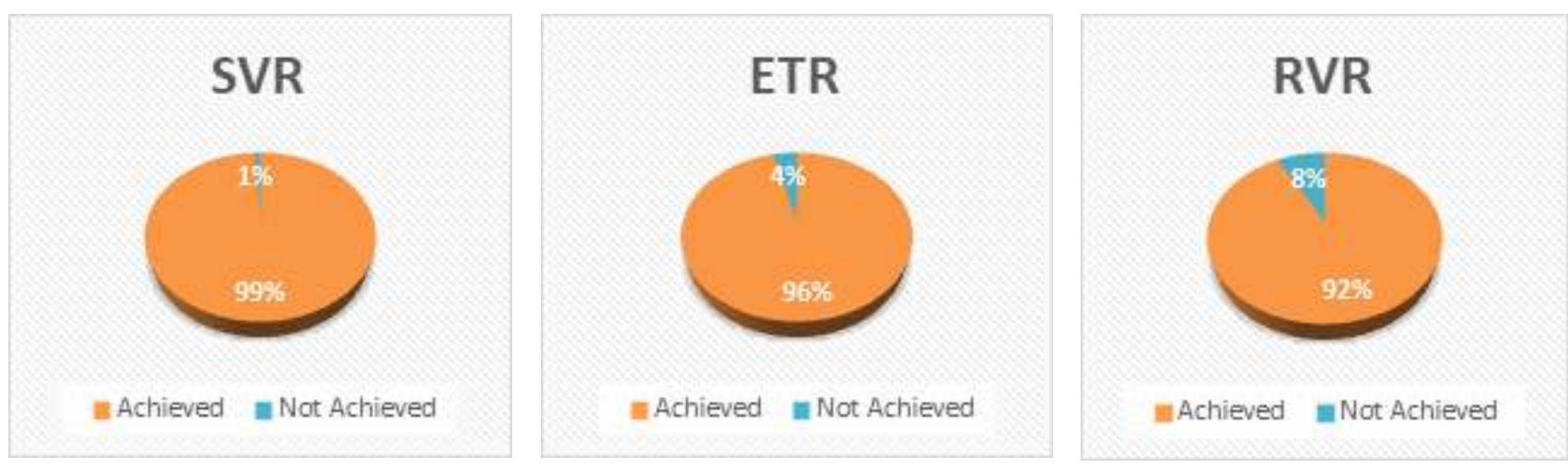

Figure-III 
Table-I. RVR, ETR SVR status after stratification.

\begin{tabular}{|l|l|l|l|l|}
\hline \multicolumn{2}{|c|}{ Age } & \multicolumn{1}{c|}{ RVR } & \multicolumn{1}{c|}{ ETR } & \multicolumn{1}{c|}{ SVR } \\
\hline \multirow{2}{*}{ Gender } & $18-45$ years & $55 / 60(90 \%)$ & $57 / 60(95 \%)$ & $60 / 60(100 \%)$ \\
\cline { 2 - 5 } & $46-70$ years & $37 / 40(92.5 \%)$ & $39 / 40(97.5 \%)$ & $39 / 40(97.5 \%)$ \\
\cline { 2 - 5 } & Male & $47 / 51(92.1 \%)$ & $49 / 51(96 \%)$ & $50 / 51(98 \%)$ \\
\cline { 2 - 5 } & Female & $45 / 49(91.8 \%)$ & $47 / 49(95.9 \%)$ & $49 / 49(100 \%)$ \\
\hline \multirow{2}{*}{ BMI } & $18.5-24.9$ & $67 / 73(91.7 \%)$ & $70 / 73(95.8 \%)$ & $73 / 73(100 \%)$ \\
\cline { 2 - 5 } & $25-29.9$ & $25 / 27(92.5 \%)$ & $26 / 27(96.3 \%)$ & $26 / 27(96.3 \%)$ \\
\hline
\end{tabular}

\section{DISCUSSION:}

$\mathrm{HCV}$ infection has emerged as a significant global problem as its burden is on rise with passage of time. This disease is no more confined to few epidemiological locations, rather it is now considered to be present in almost every country of world contributing to socio-economic burden ${ }^{[10]}$.

Most widely studied genotype across the world is Genotype 1, and majority research data is targeted to this Genotype. However Genotype 3 has also been focused in studies especially due to its resistance to conventional treatment regimes. Developments of new oral antiviral drugs have made treatment of genotype 3 much easier. And these newer medications like sofosbuvir and related compounds are now hot favorite in the treatment of HCV genotype $3^{[11,}$ ${ }^{12]}$. It has been reported that patients infected with HCV genotype 3 are more prone to develop Hepatocellular carcinoma as compared to patients infected with HCV genotype 1 . In a study by Kanwal $F$, et al ${ }^{[13]}$ was found that this association of HCV genotype and HCC is independent of patients' age, diabetes, body mass index, or antiviral treatment.

Our study conducted on a sample size of 100 persons, included both male and females in roughly equal percentage (males $51 \%$; females $49 \%$ ). There were more subjects in the younger age group (60\% in $18-45$ years age group) as compared to older age group ( $40 \%$ in $45-71$ years age group). Our study included both cirrhotic and non-cirrhotic patients. The results of our study were comparable to many other similar studies.

A series of phase 3 trials were conducted to assess efficacy of velpatasvir/Sofosbuvir with or with put ribavirin in patients of HCV genotype 1-
6 with name of ASTRAL trials. These trial encompasses both cirrhotic, non-cirrhotic as well as treatment naïve and treatment experienced patients. In ASTRAL 1 trial, 624 patients of HCV genotype 1,2,3,4 and 6 were included in trial for treatment with Velpatasvir and Sofosbuvir and overall $99 \%$ patients achieved SVR12. In ASTRAL II trial, done for HCV genotype 2, combination of Velpatasvir/ Sofosbuvir plus Ribavirin Achieved overall SVR 12 of $99 \%$. ASTRAL III was conducted for Genotype 3 of HCV in which SVR12 of $95 \%$ was recorded. Whereas in ASTRAL IV trial for patients of decompensated cirrhosis with all genotypes, SVR12 was $85 \%$ in genotype 3 with 12 weeks of treatment. Sustained Virological response (SVR 12) in our study was $99 \%$ for patients of HCV genotype including cirrhotic, non-cirrhotic, treatment naïve and treatment experienced patients after 12 weeks of therapy with Velpatasvir/ Sofosbuvir. These values are comparable to the ones seen in international studies; the slight difference might be attributed to the small sample size of our study. The evaluated Rapid Virologocal Response (RVR) and End of Treatment Responses (ETR) in our study were $92 \%$ and $96 \%$ respectively ${ }^{[6,7,8]}$. These results are also similar to results of various other international and national studies [14,15].

In another trial Velpatasvir with sofosbuvir with or without Ribavirin achieved SVR 12 in 99\% patients with HCV genotype $1,2,3^{[16]}$.

Many studies support the effectiveness of Vepatasvir plus sofosbuvir in achieving High SVR. Ahmed Husseni in a metaanalysis reported the SVR 12 in patients of HCV geotype 3 to be $94 \%$ in patients treated with Velpatasvir and Sofosbuvir ${ }^{[15]}$. ASTRAL studies also advocated that combination of Velpatasvir and 
Sofosbuvir are more effective as compared to sofosbuvir alone in achieving SVR ${ }^{[7,8]}$.

Study done by Rosito Garico et al considers Velpatasvir plus Sofosbuvir with or without Ribavirin as highly effective regimen for HCV in Cirrhotic, Liver transplant patients and patients on Haemodialysis and with renal failure ${ }^{[17]}$ .Studies done by Schreiber J etal, and Everson GT etal, reported Velpatsavir sofosbuvir combination to be highly effective ${ }^{[18,19]}$.

Currently no local study is available in our country about the efficacy of Velpatasvir and sofosbuvir in HCV genotype 3 infection, however a trial of 502 patients on Sofosbuvir in 2016 has been reported to achieve SVR12 in $85.5 \%$ of cases. However this study does not encompass for effect of Velpatasvir on SVR ${ }^{[20]}$. Another analysis by S Iqbal [21] (2017) suggested expected SVR to be between 80$100 \%$ with DAA.

In my study, the data was stratified according to age, gender and BMI. There was no effect of these parameters on the final results. Similar conclusions were drawn from clinical trials by Ferguson $\mathrm{MC}^{[22]}$.

\section{CONCLUSION}

Sustained virological response of Velpatasvir, sofosbuvir and ribavirin is encouraging. However, more studies are required to ascertain the results.

CONFLICT OF INTEREST: All authors disclose no conflict of interest.

GRANT SUPPORT \& FINANCIAL DISCLOSURES: None.

\section{REFERENCES:}

1. Messina P, Humphreys I, Flaxman A, Brown A, Cooke G, Pybus O, Barnes E. Global distribution and prevalence of hepatitis $C$ virus Genotypes, Hepatology.2015 Jan;61(1):77-87.

2. Smith DB, Pathirana S, Davidson F, Lawlor E, Power J, Yap PL, et al. The origin of hepatitis C virus genotypes. J Gen Virol. 1997;78((Pt 2)):321-328.
3. Centres for Disease Control and Prevention. Viral Hepatitis: Surveillence of viral hepatitis-united states2015 Available at https://www.cdc.gov/hepatitis/ statistics/2015surveillance/index.htm.

4. European Association for the Study of the Liver. EASL Clinical Practice Guidelines: management of hepatitis $C$ virus infection. J Hepatol 2015;63:199-201.

5. Ghany MG, Liang TJ. Current and future therapies for Hepatitis $\mathrm{C}$ virus infection. $\mathrm{N}$ Engl J Med . 2013 Aug 15.369(7): 679-80.

6. Feld JJ, Jacobson IM, Hézode C, Asselah T, Ruane PJ, Gruener N, Abergel A, Mangia A, Lai CL, Chan HL, Mazzotta F. Sofosbuvir and velpatasvir for HCV genotype 1, 2, 4, 5, and 6 infection. New England Journal of Medicine. 2015 Dec 31;373(27):2599-607.

7. Foster GR, Afdhal N, Roberts SK, Bräu N, Gane EJ, Pianko S, Lawitz E, Thompson A, Shiffman ML, Cooper C, Towner WJ. Sofosbuvir and velpatasvir for $\mathrm{HCV}$ genotype 2 and 3 infection. New England Journal of Medicine. 2015 Dec 31;373(27):2608-17.

8. Curry MP, O'Leary JG, Bzowej N, Muir AJ, Korenblat KM, Fenkel JM, Reddy KR, Lawitz E, Flamm SL, Schiano T, Teperman L. Sofosbuvir and velpatasvir for $\mathrm{HCV}$ in patients with decompensated cirrhosis. New England Journal of Medicine. 2015 Dec 31;373(27):2618-28.

9. Amjad M,Moudgal V,Faisal M. Laboratory methods for diagnosing and management of Hepatitis C virus infection. Lab Med. 7 oct 2013.44(4):292-99.

10. Chevaliez S, Pawlotsky JM. HCV genome and life cycle. InHepatitis $C$ viruses: genomes and molecular biology 2006. Horizon Bioscience.

11. American Association for the Study of Liver Diseases and the Infectious Diseases Society of America. Recommendations for testing, managing, and treating hepatitis $\mathrm{C}$. http://www.Hcvguidelines.org/full-ReportView (accessed 21 Apr 2015). 
12. Moshyk A, Martel MJ, Tahami Monfared AA, Goeree R. Cost-effectiveness of daclatasvir plus sofosbuvir-based regimen for treatment of hepatitis $C$ virus genotype 3 infection in Canada. J Med Econ. 2016;19(2):181-92.

13. Kanwal F, Kramer JR, Ilyas J, Duan Z, ElSerag HB. HCV Genotype 3 is Associated with an Increased Risk of Cirrhosis and Hepatocellular Cancer in a National Sample of U.S. Veterans with HCV. Hepatology (Baltimore, Md). 2014;60(1):98-105.

14. Safety and efficacy of sofosbuvir plus velpatasvir with or without ribavirin for chronic hepatitis $C$ virus infection: A systematic review and meta-analysis http://www.sciencedirect.com/science/art icle/pii/S1876034117302381

15. Rosita Greco, Teresa Papalia, Renzo Bonofiglio, Sp786 EFFICACY AND SAFETY OF SOFOSBUVIR AND VELPATASVIR IN RENAL TRANSPLANT RECIPIENTS WITH CHRONIC HEPATITIS C VIRUS INFECTION, Nephrology Dialysis Transplantation, Volume34,Issue Supplement_1, June 2019, gfz103.SP786, https://doi. org/10.1093/ndt/gfz103. SP786

16. High SVR rates in patients with and without cirrhosis treated in real life with Sofosbuvir/Velpatasvir (SOF/VEL) combination for 12 weeks without Ribavirin (RBV) Mangia, A. et al.Journal of Hepatology, Volume 68, S273 - S274.

17. Foster GR, Pianko S, Brown A, Forton D, Nahass RG, George J, et al. Efficacy of sofosbuvir plus ribavirin with or without peginterferon-alfa in patients with hepatitis $C$ virus genotype 3 infection and treatmentexperienced patients with cirrhosis and hepatitis C virus genotype 2 infection. Gastroenterology. 2015;149(6):1462-70.

18. Schreiber J, McNally J, Chodavarapu K, Svarovskaia E, Moreno C. Treatment of a patient with genotype 7 hepatitis $C$ virus infection with sofosbuvir and velpatasvir. Hepatology. 2016;64(3):983-5.
19. Everson GT, Towner WJ, Davis MN, Wyles DL, Nahass RG, Thuluvath PJ, et al. Sofosbuvir With Velpatasvir in TreatmentNaive Noncirrhotic Patients With Genotype 1 to 6 Hepatitis C Virus Infection: A Randomized Trial. Ann Intern Med. 2015;163(11):818-26.

20. Akhter TS, Umar M, Khaar HT, Aslam F, Nisar G, Naseer A, et al. Sofosbuvir For The Treatment Of Hepatitis C Genotype 3 Infected Patients In Pakistan. J Ayub Med Coll Abbottabad. 2016;28(4 Suppl 1):S884-S89.

21. Iqbal S, Yousuf MH, Yousaf MI. Dramatic response of hepatitis $C$ patients chronically infected with hepatitis $C$ virus genotype 3 to sofosbuvir-based therapies in Punjab, Pakistan: A prospective study. World J Gastroenterol. 2017;23(44):7899-905.

22. Ferguson MC. Sofosbuvir with ribavirin is safe and effective in hepatitis $C$ genotype 1 with unfavourable pretreatment characteristics. Evid Based Med. 2014;19(3): 90 .

\section{Authors' Contribution:}

Muhammad Sarfraz: Designed, data collection, statistical analysis, final approval of manuscript, and agreement for accountability of all work.

Arshad Rabbani: Data collection, statistical analysis, agreement for accountability of all work, and final approval of manuscript.

Muhammad Shahzad Manzoor: Over all Supervision of data collection, analysis and study writing.

Benish Adil: Help in data collection analysis and final draft of study.

Ramsha Ghazal Arshad: Help in data collection analysis and final draft of study.

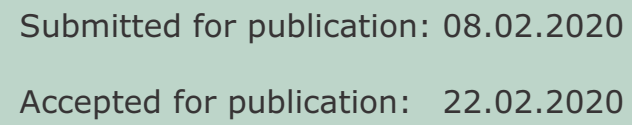

